Article

\title{
The Use of High-Alloyed EAF Slag for the Neutralization of On-Site Produced Acidic Wastewater: The First Step Towards a Zero-Waste Stainless-Steel Production Process
}

\author{
Mattia De Colle*(D), Pär Jönsson, Andrey Karasev, Alicia Gauffin $\mathbb{D}$, Agnieszka Renman $(\mathbb{D}$ \\ and Gunno Renman (D) \\ KTH Royal Institute of Technology, SE-100 44 Stockholm, Sweden; parj@kth.se (P.J.); karasev@kth.se (A.K.); \\ aliciag@kth.se (A.G.); agak@kth.se (A.R.); gunno@kth.se (G.R.) \\ * Correspondence: mattiadc@kth.se; Tel.: +46-765768409
}

Received: 12 August 2019; Accepted: 11 September 2019; Published: 23 September 2019

check for updates

Featured Application: Waste valorization in the production process of scrap-based stainless-steel.

\begin{abstract}
Recycling of steelmaking slags has well-established applications, such as their use in cement, asphalt, or fertilizer industries. Although in some cases, such as the electric arc furnace (EAF) high-alloyed stainless-steel production, the slag's high metal content prevents its use in such applications. This forces companies to accumulate it as waste. Using concepts such dematerialization, waste management, industrial symbiosis, and circular economy, the article drafts a conceptual framework on the best route to solving the landfilling issue, aiming at a zero-waste process re-design. An experimental part follows, with an investigation of the use of landfill slag as a substitute of limestone for the neutralization of acidic wastewater, produced by the rinsing of steel after the pickling process. Neutralization of acidic wastewater with both lime and slag samples was performed with two different methods. Two out of four slag samples tested proved their possible use, reaching desired $\mathrm{pH}$ values compared to lime neutralizations. Moreover, the clean waters resulting from the neutralizations with the use of both lime and slag were tested. In terms of hazardous element concentrations, neutralization with slag yielded similar results to lime. The results of these trials show that slag is a potential substitute of lime for the neutralization of acidic wastewater.
\end{abstract}

Keywords: EAF slag; recycling; re-use; wastewater treatment; sustainable production; dematerialization; zero waste; circular economy

\section{Introduction}

Human influence on the environment has been so strong in the latest centuries that the label for a new geological era, the "Anthropocene", has been used to describe the period following the invention of the steam engine in 1784 [1]. More conceptual work followed, refining the idea of the current unsustainability in the manufacturing sector, by calculating the limits to anthropogenic actions, defining nine planetary boundaries: indexes describe the thresholds above which the production of goods is no longer sustainable and can lead to changes in the environment as we know it [2]. Moreover, the European Union identified the generation of waste as a crucial threat to sustainability, which lead policy makers into streamlining a common list of waste management operations, from most to least desirable [3]. This directive is known as the European Waste Hierarchy (EWH), and it holds its foundation on the pioneer work of A. Lansink, started in 1979 [4]. According to this set of policies, 
landfilling is the least desirable option, and it should be avoided as much as possible. The need for proper waste management, for any manufacturing business, calls for immediate solutions in sectors where landfilling is still the primary option. It is with this context in mind that this article was written. The use of slag, to buffer and increase the $\mathrm{pH}$ of on-site produced acid wastewater to benefit a circular economy and by-product valorization, was studied.

In this study, the overall objective was to investigate whether slag is an effective replacement for slaked lime, since according to the principles of dematerialization this would allow the decoupling from raw materials and reduce also the material flow to landfills [5]. The stainless-steel production processes of two steel mills in Sweden, Outokumpu Stainless (OTK) and Sandvik Materials Technology (SMT), were used as case studies. Both companies produce high-alloyed slags which, in the most part, are landfilled. In this study, it was investigated if it was possible to re-use landfill slag to neutralize acidic wastewater at the respective steel mill. A total of two slag types from each steel mill were selected and evaluated for their ability to neutralize acidic wastewater produced at the steel mills. The results were also compared with the neutralization performed with the lime products currently used at the steel mills. Besides the ability to raise the $\mathrm{pH}$ to desired value, the slag should also be able to remove metals from the wastewater. Such a property was tested in additional trials.

In Sweden, almost $2000 \mathrm{kt}$ of by-products were produced by iron and steelmaking businesses in 2015 alone [6]. Currently, more than $80 \%$ of the total amount of iron and steelmaking residues are valorized. However, specific sectors of steelmaking are struggling more than others to find an adequate solution, as shown in Figure 1. In most of the sectors listed, the handling of these products, either by internal or external use, almost completely matches the produced amount. Despite this fact, there are some critical types of by-products that find little no to application and are currently landfilled.

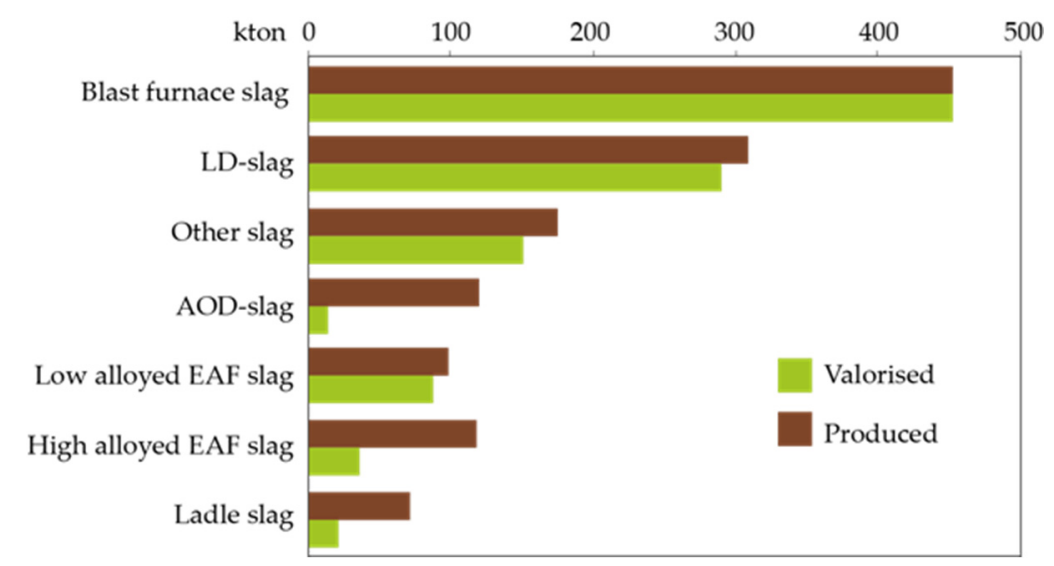

Figure 1. Production and handling of metallurgical slags from iron and steel mills in Sweden during the year 2015. Reproduced with permission from [5], Copyright Jernkontoret, 2018.

Slag derived from the production of high-alloyed electric arc furnace (EAF) stainless-steel, argon oxygen decarburization (AOD) slag, and ladle slag currently suffer from the incapability of being properly valorized. By comparing Figure 1 with Figure 2, it is clear that the reason why the handling of these products is hindered is their alloying elements content. In fact, the most common use for iron and steelmaking slag is the cement and asphalt industry [7]. However, when the materials present high concentrations of metallic or heavy elements, leaching can occur, which impedes the use of these materials for applications where they are subject to weathering [8]. Moreover, EAF slags present phenomena of swelling and disintegration that further impede their use in these types of applications, e.g., asphalt [9]. Therefore, if these products cannot access the market as secondary raw materials via the conventional recycling routes, novel applications need to be drafted to avoid landfilling and increase the sustainability of these processes. 


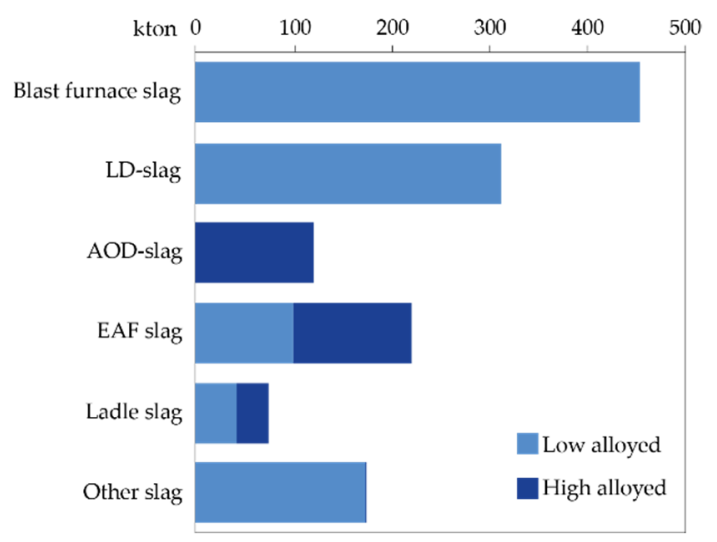

Figure 2. Production of metallurgical slag from the iron and steel mills during the year 2015. Reproduced with permission from [5], Copyright Jernkontoret, 2018.

\section{The Use of Slag as a Substitute for the Lime Products Used for the Neutralization of On-Site Produced Acidic Wastewater}

Neutralization of acidic wastewater with the use of slaked lime is a well-established and effective process [10] used by both OTK and SMT. Both companies produce acidic wastewater, formed by the rinsing of steel after their respective pickling processes. Lime derived from calcareous limestone is cheap and abundantly produced. It is also applied in other parts of the steelmaking process, thus creating no incentives to stop its use, translating into a situation of technological "lock in" [11], even though the necessity of recirculating slag highlights an opportunity to change the current technology. An inductively coupled plasma mass spectrometry (ICP-MS) analysis has been performed on different slags taken from different parts of the steelmaking processes, both at OTK and SMT [12]. The analysis revealed that all the slag samples presented a calcium content of $30 \mathrm{wt} \%-40 \mathrm{wt} \%$. Calcium (Ca) in slag has already been identified as the main contributor for the neutralization of acidic solutions [13]; hence, it could be tested as a viable substitute for lime in the neutralization process at OTK and SMT, as well as in other stainless-steel plants.

Figure 3 shows the current lime and slag routes at OTK and SMT. Slag, due to the lack of a suitable use, is produced in the steelmaking process and landfilled. Moreover, wastewater is collected after the pickling process and sent to the neutralization plant for treatment. There, with the use of lime, the $\mathrm{pH}$ is raised from $\sim 2$ to neutral values, while almost all the metal particles dissolved in the water are absorbed by the same neutralizing agent. Solid residues, derived from the chemical reactions between the wastewater and lime ("saturated lime" in Figure 3 and from now on called "sediments"), are filtered away from the clean waters, pressed, dried, and ultimately landfilled. Furthermore, cleaned water is released into the municipal streams. There are two major differences between the processes used by the two companies. Before landfilling, metal extraction is performed on the SMT slag to recover as many alloying elements as possible, while OTK do not landfill their sediments, rather they processes them and recirculate them as slag formers in the melt shop.

Once the current process has been analyzed, it is possible to theorize what changes need to be applied to ensure an internal recirculation of slag. As shown in Figure 4, slag is used instead of lime for the neutralization of the acidic wastewater. This has multiple advantages: first, there is a net reduction in the material input, which is a clear gain in terms of resource efficiency. Decoupling from the use of lime means not only an economical advantage for the companies, but also an increased sustainability of the overall process. Second, by using slag as a neutralizing agent it is possible to increase the concentration of valuable alloying elements in it. Although this could be a disadvantage, it could be turned into an asset if we consider the state of the art of slag recycling. The wastewater contains, among others, $\mathrm{Cr}, \mathrm{Ni}, \mathrm{Mo}, \mathrm{Fe}$, and $\mathrm{F}$, which, if the neutralization processes work, end up in the slag. The high concentration of metals in the slag, which has previously been considered a liability for cement or asphalt applications due to the leaching phenomenon, can become an advantage if the 
by-product with its alloying elements is used in the steelmaking process. If the sediments of the reacted slag are successfully reused in the melt shop, the material losses due to landfilling of by-products can be diminished. However, it can be expected that recirculating landfilled slag will likely result in degradation of the material properties over time and its efficiency in the steelmaking process. In fact, in the AOD process (which is part of the stainless-steel making route) unwanted elements such as $\mathrm{S}$ are reduced in the slag. This means that it is unlikely that the by-product could be brought back in the melt shop multiple times, without further treatment. Therefore, $\mathrm{S}$ extraction by pyro- or hydro-metallurgy is likely necessary for the closing the loop of slag.

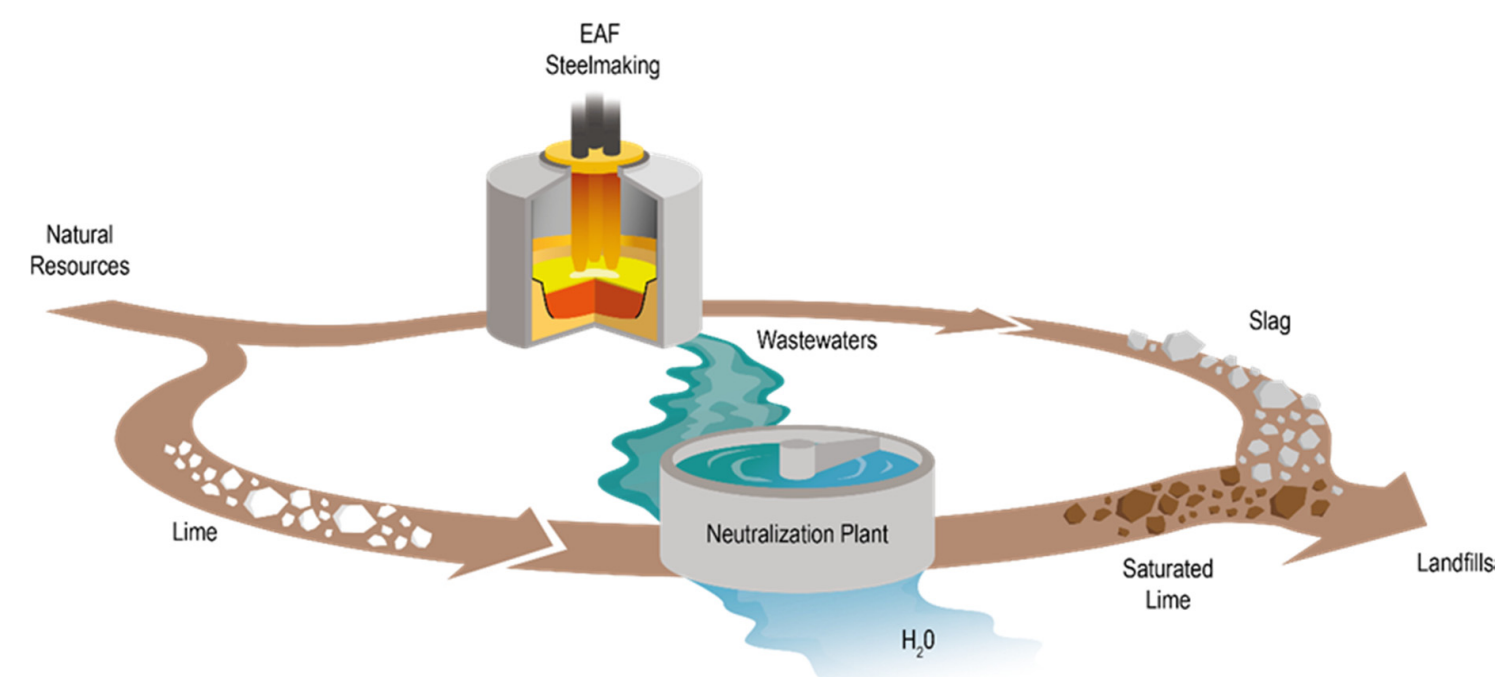

Figure 3. Schematic illustration of the lime and slag routes of the Outokumpu Stainless (OTK) and Sandvik Materials Technology (SMT) steelmaking processes.

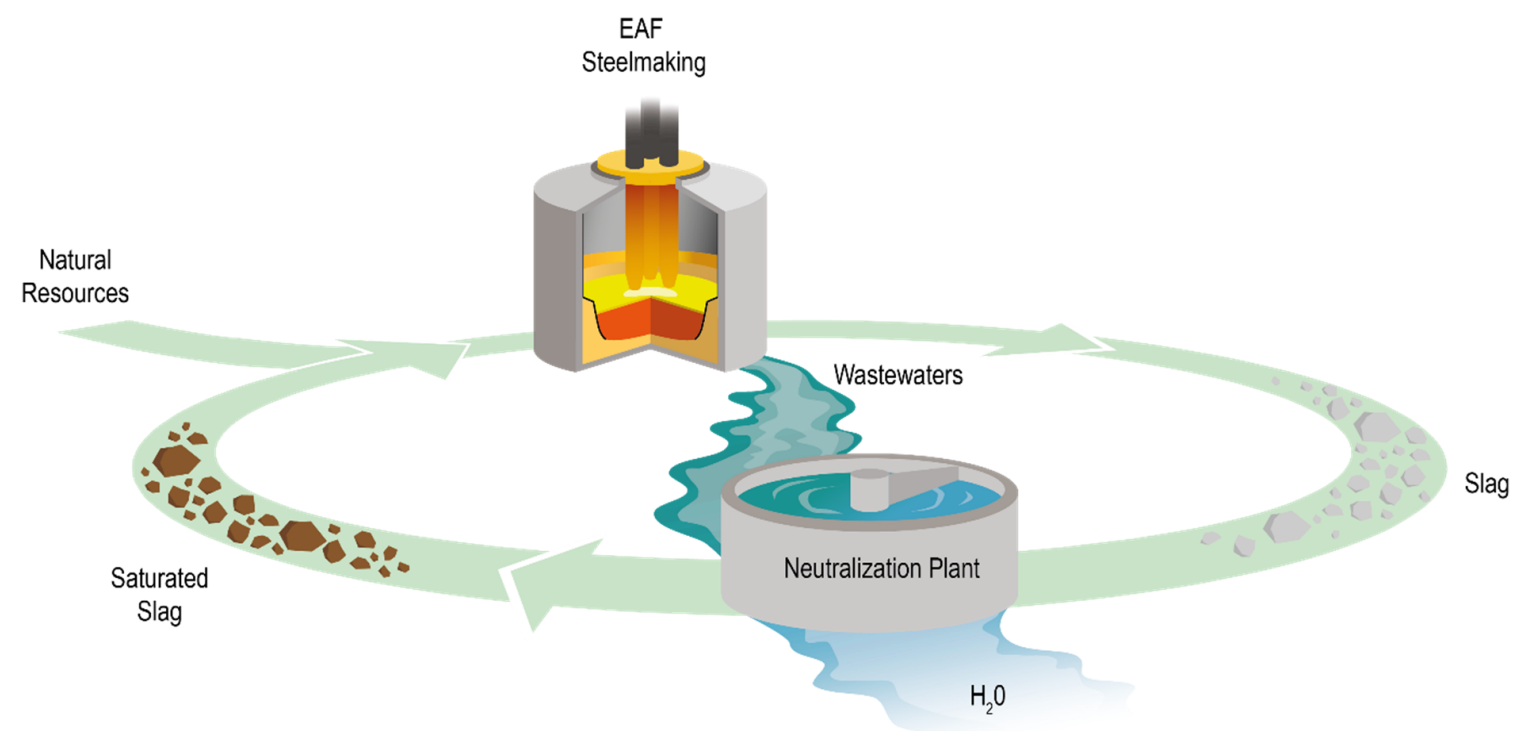

Figure 4. The by-products route with an internal recirculation of slag.

\section{Materials and Methods}

\subsection{Materials, Sample Preparation, and Characterization}

As previously mentioned, to maintain an applied approach of research, the minimum amount of alterations on the materials were performed. However, one slag sample per each company (namely $\mathrm{O} 2$ and S2) was retrieved in big solid chunks and needed to be crushed in order to be used for the 
neutralization trials. The method used was a three-step crushing, with the use of a jaw crusher, a spider crusher, and finally a horizontal impact shaft. The other two samples were retrieved from the companies' landfills (O1 and S1) and were already fine enough powders, but they presented a high level of wetness; hence, they needed to be dried before use in trials. The samples were stored in an oven at $100^{\circ} \mathrm{C}$ for $24 \mathrm{~h}$. After crushing and drying, all samples were sieved through a $1 \mathrm{~mm}$ mesh to remove all the rocks that were retrieved along with the slags. All the materials that passed through the mesh were used for the trials. Lime samples did not require any preparation before being used. The investigated materials and the performed processing are presented in Table 1.

Table 1. List of materials used and how they were processed before trials.

\begin{tabular}{ccccc}
\hline Material & Description & Drying & Crushing & Sieving (1 mm) \\
\hline O1 & OTK Landfill slag & $\checkmark$ & - & $\checkmark$ \\
O2 & EAF slag & - & $\checkmark$ & $\checkmark$ \\
S1 & SVK Landfill slag & $\checkmark$ & - & $\checkmark$ \\
S2 & AOD slag & - & $\checkmark$ & $\checkmark$ \\
OL & OTK Lime & - & - & - \\
SL & SMT Lime & - & - & - \\
\hline
\end{tabular}

\section{Particle Size Distribution Analysis}

Considering the diverse nature and the different operations performed on all the material used during the trials, a different particle size distribution was expected. Thus, to be able to compare slag and lime neutralization trials, a particle size distribution analysis (PSD) was performed by laser diffraction in air media. The analysis is presented in Figure 5.

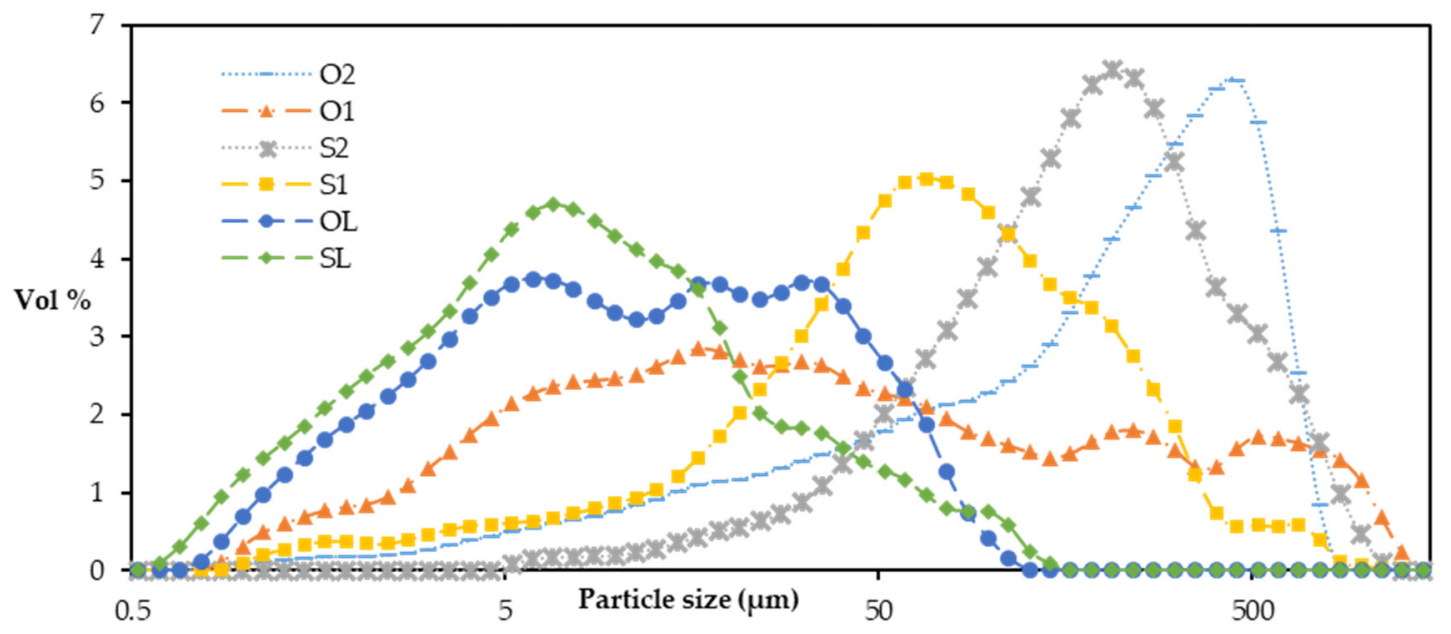

Figure 5. Particle size distribution (PSD) analysis of the investigated materials.

It is noticeable that the slag samples that had been crushed, such as $\mathrm{O} 2$ and S2, were remarkably coarser than the rest of the samples. In addition, they had a much narrower PSD. On the other hand, the $\mathrm{O} 1$ sample presented values across the whole spectrum while remaining on average finer than the crushed samples. The wide range is to be attributed to the fact that the $\mathrm{O} 1$ sample was a slag generated by water quenching, and its nature was not artificially modified by any crushing technique. The PSD of sample S1 was in between both crushed samples and the $\mathrm{O} 1$ sample. This is to be attributed to the metal extraction process performed at SMT, which requires grinding as one of the steps. Lime samples presented an even finer particle size distribution than O1 and S1. 


\subsection{Experimental Setup}

To perform the neutralization trials, a simple experimental setup was designed. Regardless of the method of adding the reactant, the neutralization trials were performed according to the following method. One liter of wastewater was poured into an Erlenmeyer flask that was subsequently placed on top of a magnetic stirrer. After a magnet was placed at the bottom of the flask, the magnetic stirrer was activated and set to an arbitrary speed, which was always kept constant between trials. An arbitrary amount of reactant was weighed and dropped into the flask. Subsequently, the stopwatch was started. More additions were made if the investigation method required it. $\mathrm{pH}$ measurements (conducted with the model "sensION p31" calibrated at the start of each trial day with the use of buffers at a pH of 4.01, 7.01, and 10.01) were performed at different times depending on the investigation method until the final $\mathrm{pH}$ value was reached. To sample the $\mathrm{pH}$, a rubber tube was inserted in the flask, and without interrupting the stirring with the use of the syringe, around $20 \mathrm{~mL}$ of wastewater were taken each time to do the $\mathrm{pH}$ measurements. Once the $\mathrm{pH}$ was measured, a small wastewater sample was poured back into the flask. The flocculants currently used by the companies in their full-scale processes were added to coalesce the sediments. Then, with the use of filter papers and a funnel, clean waters were separated from the solid particles. Wastewater and clean waters after the neutralization, along with the sediments, were sampled for later studies.

\subsubsection{Trial With Stepwise Dosing of Reactant}

The rationale behind this trial was to understand the order of magnitude needed for each reactant (lime included) to successfully buffer one liter of wastewater to $\mathrm{pH}$ 9. In order to do so, very small additions of reactant were added to the wastewater, and the reaction was maintained until a semi-state of equilibrium between the reactant and the waters was reached (depicted EQ), according to the following experimental procedure:

1. At $t=0$ a very small amount of reactant of known weight was added to the wastewater.

2. At $\mathrm{t}=10 \mathrm{~min}, \mathrm{t}=20 \mathrm{~min}$ the $\mathrm{pH}$ value was measured.

3. At $t=30$ min the $\mathrm{pH}$ value was measured again, if $\left|\mathrm{pH}_{30}-\mathrm{pH}_{20}\right| \leq 0.3$, a new quantity of reactant was added and the procedure repeated. Otherwise, the $\mathrm{pH}$ was measured again $10 \mathrm{~min}$ later until $\left|\mathrm{pH}_{\mathrm{i}+10 \text { min }}-\mathrm{pH}_{\mathrm{i}}\right| \leq 0.3$.

4. When the $\mathrm{pH}$ was $9 \pm 0.2$, the trial was stopped, and the total amount of reactant used was calculated.

A final $\mathrm{pH}$ of 9 is desired because the industrial neutralization process both at OTK and SMT requires to reach such value. This is because the absorption of some elements (such as Ni) from the reactant are maximized at high $\mathrm{pH}$ levels - hence the need to pass beyond neutral values towards basic ones to increase the absorption of such elements. All six reactants were tested, and duplicates were made if the first trial proved successful.

\subsubsection{Single Dosing of Reactant}

A single dosing of reactants was applied in a second set of trials labelled AIO ("all in one"), which aimed to mimic the currently used full-scale process at OTK and SMT, where lime is added in one big dose at the beginning of the process, with minor adjustment to reach the target value later on. The trial also mimics the retention time of wastewater in the full-scale facility, which is approximately $30 \mathrm{~min}$. With this information in mind, AIO trials were performed according to the following procedure:

1. Starting from the quantity measured during the EQ trials, an amount of reactant of known weight as mixed with the wastewater at $\mathrm{t}=0 \mathrm{~min}$.

2. The $\mathrm{pH}$ was measured at $\mathrm{t}=2,5,10,15,20,25,30,40,50$, and $60 \mathrm{~min}$. 
3. If the trials reached $\mathrm{pH} 9 \pm 0.2$ at the 30 min mark, the trial was considered successful. Otherwise a following trial was performed using a different quantity of reactant, depending on the $\mathrm{pH}$ level previously obtained.

In this case, a trial was considered successful only if it could reach a $\mathrm{pH}$ of $\sim 9$ within $30 \mathrm{~min}$. A procedure of trial and error was used to find the optimal quantity for the AIO. Only the reactants that during the EQ reached a $\mathrm{pH}$ of 9 were used for the AIO trial.

\subsubsection{Water Purity Trials}

To test the purity of the clean waters produced, six additional AIO trials were performed. Wastewater samples were analyzed using ICP-MS before and after the neutralization. The concentrations of $\mathrm{Cr}$, $\mathrm{Ni}, \mathrm{Fe}, \mathrm{Mo}, \mathrm{F}$, and $\mathrm{Zn}$ were tested and confronted with the threshold allowed by the municipal laws of Avesta (Sweden), the place where OTK's steel mill resides. For this test, only wastewater samples coming from OTK's neutralization facility $(\mathrm{O} 1, \mathrm{OL})$ were used. Table 2 summarizes all the parameters used during the AIO to test the water purity after lime and slag neutralization.

Table 2. Mass of material and volume of flocculant used during the water purity all in one (AIO) trials.

\begin{tabular}{cccc}
\hline Trial Name & Material & Mass $(\mathrm{g})$ & OTK Flocculant $(\mathbf{m L})$ \\
\hline OL-1 & OL & 5.5 & 3.0 \\
OL-2 & OL & 5.4 & 3.0 \\
OL-3 & OL & 5.5 & 3.0 \\
O1-1 & O1 & 43.9 & 0.5 \\
O1-2 & O1 & 43.8 & 1.0 \\
O1-3 & O1 & 43.8 & 0.5 \\
\hline
\end{tabular}

\section{Results and Discussion}

\subsection{Stepwise Dosing}

The results of the stepwise dosing trials are shown in Table 3. Duplicate trials were carried out for the materials that were able to successfully reach a $\mathrm{pH}$ of 9 in the first trials. This category includes all the materials listed, but $\mathrm{O} 2$ and $\mathrm{S} 2$ did not reach the $\mathrm{pH}$ target value. In their case, the trials were stopped after several iterations, because the $\mathrm{pH}$ value plateaued despite the addition of more slag. The remaining four materials demonstrated that, given the experimental setup, they were able to raise the $\mathrm{pH}$ of the acidic wastewater to the desired values. The duplicates also guarantee replicability of the results, showing similar quantities and final $\mathrm{pH}$ levels between trials.

Table 3. Results of the stepwise dosing trials.

\begin{tabular}{cccc}
\hline Trial Name & Material & Final $\mathbf{p H}$ & Total Mass $(\mathbf{g})$ \\
\hline OL-1 & OL & 10.68 & 4.79 \\
OL-2 & OL & 11.35 & 4.83 \\
SL-1 & SL & 9.35 & 6.33 \\
SL-2 & SL & 9.36 & 6.47 \\
S1-1 & O1 & 9.09 & 22.80 \\
S1-2 & O1 & 9.40 & 28.56 \\
O11-1 & S1 & 9.08 & 23.60 \\
O11-2 & S1 & 9.01 & 23.30 \\
O2 & O2 & 5,76 & 32.20 \\
S2 & S2 & 5.28 & 36.30 \\
\hline
\end{tabular}

The EQ trials showed that different quantities of slag and lime are needed to successfully reach a $\mathrm{pH}$ of 9. This can be attributed to two different factors, namely the particle size distribution and 
mineral composition (which is believed to be different, considering the different origins of the samples). Regarding the first, it is noticeable how a coarser PSD led to a higher amount of reactant needed for the neutralization. This can easily be explained by considering that a coarser particle has a lower surface/volume ratio. Hence, considering that the reactant does not completely dissolve, not all the $\mathrm{Ca}$ present in the material is able to react with the wastewater, leading to a higher amount of material needed. Moreover, the mineral composition, despite unknown, is believed to play an important role. If $\mathrm{Ca}$ is the element that drives the neutralization process [13], it is also clear that a different $\mathrm{w} \%$ of said element and how it reacts with the wastewater based on the mineral structure are key factors. These two factors combined explain why both lime samples, which present a higher Ca content compared to slag and a finer PSD, neutralize one liter of wastewater with approximately four to six times less the amount of $\mathrm{O} 1$ and $\mathrm{S} 1$ sample.

Regarding the behavior of $\mathrm{O} 2$ and S2, the authors believe that the data collected is not enough to rule them out as suitable reactants. Both slag samples have a higher PSD compared to the remaining materials, and that could impede the neutralization. Moreover, the trials were stopped after several iterations because the $\mathrm{pH}$ increases were not substantial enough. However, that does not mean that a successful neutralization could not have been obtained with higher amounts and more time. More experiments with a reduced PSD are needed to test the material again, possibly homogenizing the particle size to the one of $\mathrm{O} 1$ and $\mathrm{S} 1$ samples or even the lime samples.

\subsection{Single Dosing Trial}

The AIO trials for the lime samples are presented Figure 6. All six trials show a similar trend were there is an abrupt surge in the $\mathrm{pH}$ level, followed by a plateau for the remaining part of the trial. Specifically, more than $90 \%$ of the final $\mathrm{pH}$ value were reached before $10 \mathrm{~min}$ from the beginning of the measurements.

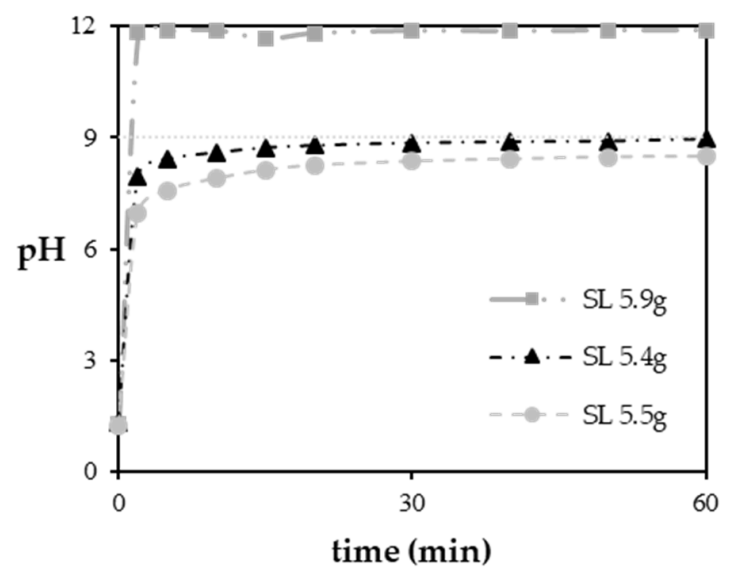

(a)

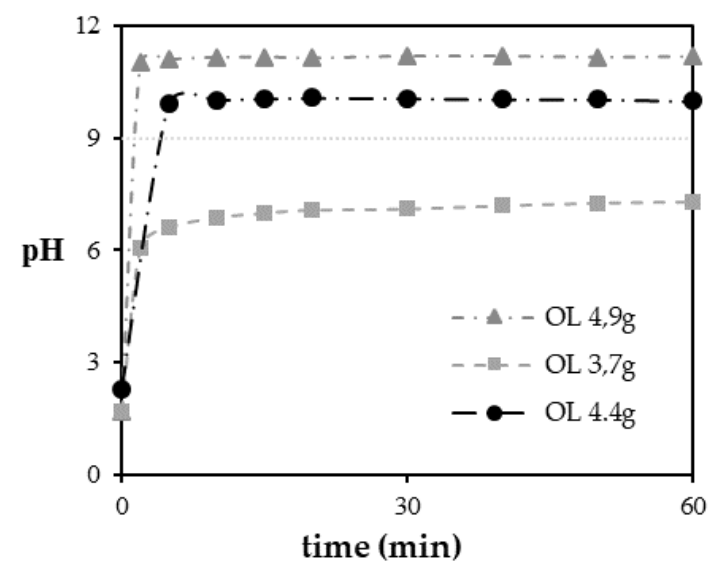

(b)

Figure 6. Results of all in one (AIO) trials performed with SL (a) and OL (b).

The quantities of both lime samples used during AIO trials coincided with the ones used for the EQ ones. A potential interpretation is that the reaction kinetics between lime and wastewater are so fast that the difference in the two trials did not yield different results. The same does not apply for the slag samples tested. As previously mentioned, only the slag samples that reached a $\mathrm{pH}$ of 9 during the EQ trials were tested in the AIO trails, meaning that only neutralization trials with $\mathrm{O} 1$ and $\mathrm{S} 1$ were performed. The behavior of slag neutralization can be seen Figure 7. All six samples show a similar trend, with an abrupt surge in $\mathrm{pH}$ at the beginning of the trial, followed by a stable phase. Thereafter, the $\mathrm{pH}$ values rose again and stabilized at the final $\mathrm{pH}$ value later in the trial. This double-plateau system looks mass dependent: the trial with the fewer grams of slag used $(\mathrm{O} 128 \mathrm{~g}$ 
and S1 39g) present the second rise later in time than the ones with more mass. Despite both of those trials reaching the target value of 9 by minute 60, they did not do it quickly enough for the $30 \mathrm{~min}$ mark, thus a higher amount of slag is needed. The reaction's kinetics impacts the slag neutralization in a negative way, and the time restrictions affect the amount of slag that is needed to successfully neutralize the wastewater. Approximately twice the amount of slag and around 8-10 times the amount of lime previously measured in the EQ trials was needed in the AIO trails.

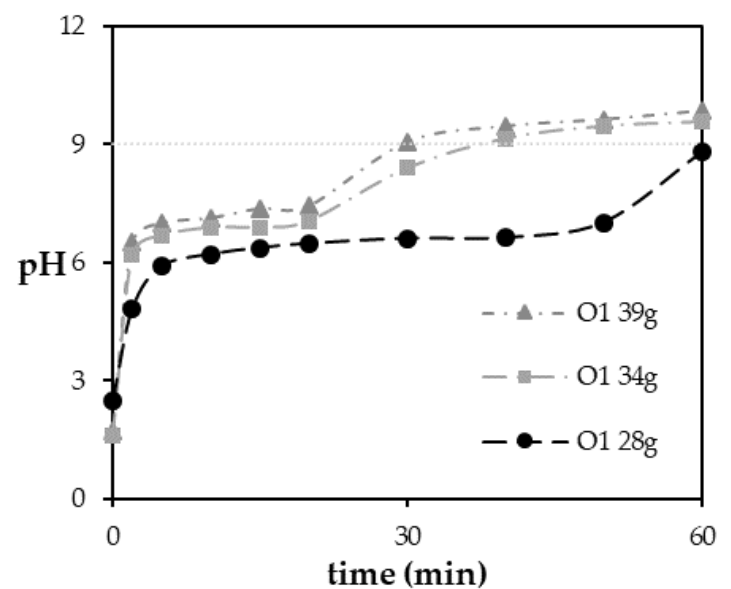

(a)

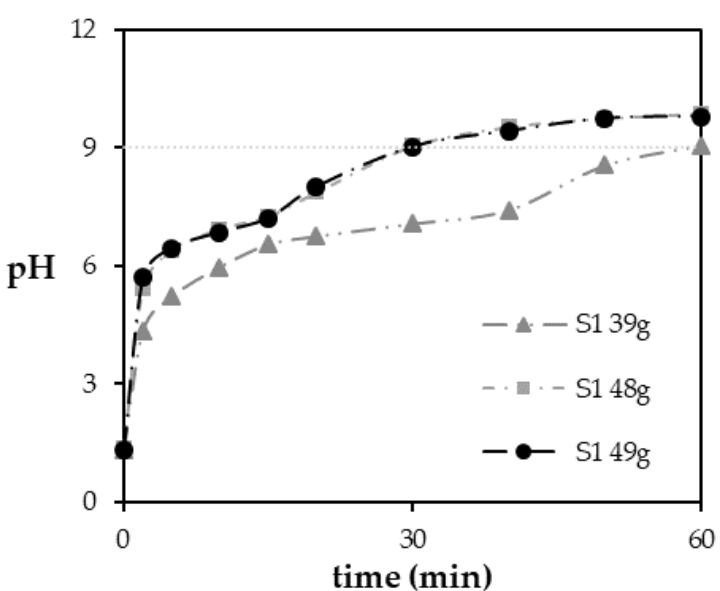

(b)

Figure 7. Results of AIO performed with $\mathrm{O} 1$ (a) and S1 (b).

As for the EQ trials, the hypothesis was that $\mathrm{Ca}$ is the main contributor to the neutralization of the acidic content in the wastewater during the AIO trials. This means that the more accessible this element becomes, the less slag is needed. Therefore, it is believed that both PSD and mineral composition are impacting factors of $\mathrm{Ca}$ availability to the neutralization. The first factor is easily explained by the surface area/volume ratio. Since it has been observed that a total dissolution of the slag particles does not occur, the smaller the particles, the more $\mathrm{Ca}$ is available to react with the wastewater on the surface or in its proximity. The second factor, the mineral composition, could also meddle with availability of Ca to react. In fact, it is fair to assume that depending on where on the crystal lattice the Ca atoms are placed, they have a different dissolution rate when in contact with the acid environment. Nonetheless, targeted experiments are needed in order to test these hypotheses and understand the impact of several slag's characteristics and how the neutralization mechanism works.

\section{Water Purity Trials}

If slag was used as a slaked lime substitute, another factor must be evaluated: the level of toxins in the remaining water to be released into the environment. In fact, a successful reactant not only increases the $\mathrm{pH}$ by neutralizing the acidic content of the wastewater, but also absorbs many dissolved elements that can be harmful for the environment. The results from the ICP-MS tests on the clean waters derived from the second set of AIO, along with the chemical composition of the original neutralized wastewater, and the threshold allowed by the Swedish regulatory laws are presented in Table 4.

It is clear from the data that the same purification effect is equally achievable with both slag and lime. Around $99 \%$ of the $\mathrm{Cr}, \mathrm{Ni}$, and Fe dissolved in the wastewater are absorbed both by lime and slag, resulting in final values lower than the permitted ones. Mo is absorbed less than the other elements. Its quantity present in the wastewater is not as high as to begin with, but the absorbing capacity of both reactants is reduced. Despite the fact that there is no threshold regulating the amount of $F$ to be released, it is of interest for future research to evaluate how much of the element is trapped in the reactant. In fact, OTK recirculates their sediments as slag builders, and $\mathrm{CaF}_{2}$ is a key compound 
to ensure their usage in the furnace because it decreases the viscosity of the slag and facilitates the reactions between it and the steel bath.

Table 4. Results of the AIO for the water purity tests.

\begin{tabular}{ccccccc}
\hline & $\mathbf{C r}(\mathbf{m g} / \mathbf{L})$ & $\mathbf{N i}(\mathbf{m g} / \mathbf{L})$ & $\mathbf{M o}(\mathbf{m g} / \mathbf{L})$ & $\mathbf{F}(\mathbf{m g} / \mathbf{L})$ & $\mathbf{F e}(\mathbf{m g} / \mathbf{L})$ & $\mathbf{Z n}(\mathbf{m g} / \mathbf{L})$ \\
\hline Wastewater & 434 & 358 & 42 & 1230 & 664 & 0.8 \\
OL-1 & 0.08 & 0.18 & 12 & 5.7 & 0.12 & $<0.05$ \\
OL-2 & 0.07 & 0.32 & 7.2 & 5.8 & 0.07 & $<0.05$ \\
OL-3 & 0.1 & 0.32 & 7.6 & 5.1 & 0.17 & $<0.05$ \\
O1-1 & 0.12 & 0.27 & 7.3 & 7.9 & $<0.05$ & $<0.05$ \\
O1-2 & 0.19 & 0.37 & 9 & 10.5 & $<0.05$ & $<0.05$ \\
O1-3 & 0.08 & 0.32 & 7.2 & 8.7 & $<0.05$ & $<0.05$ \\
Threshold & 0.5 & 0.5 & 10 & - & 1 & - \\
\hline
\end{tabular}

In addition, it is worth noting how important it is for circularity and sustainable production to recirculate the sediments in the steelmaking process. Not only is waste prevented by finding an internal use of the materials previously discarded, but they also limit material losses by capturing precious alloying elements.

\section{Conclusions and Future Work}

This article shows how the concepts of sustainable production, process eco-design, and waste management can help practitioners in the steelmaking industry to improve the sustainability of their whole sector, by setting a conceptual framework for new technological ideas. The authors used a top to bottom approach by first highlighting a sustainability problem, such as the excessive landfilling of slag in the stainless-steel production. Thereafter, the article continued with presenting a technical application that would follow such guidelines. Furthermore, through a conceptual analysis, a whole re-design of two stainless-steel manufacturing process was presented. Outokumpu Stainless (OTK) and Sandvik Material Technologies (SMT) were used as study cases for such an analysis. The general vision that was described also provides a guideline for future research, explaining the needs for such choices and stressing the importance of acting in such a way.

After the theoretical part, experimental trials aimed at testing the applicability of the vision were presented. As a preliminary investigation, two slag samples from each company, their limestone samples, and wastewater were used to perform neutralization trials in small-batch tests. The primary goal of such investigation was to compare the slaked lime used by the companies to their slag. Moreover, the focus was also to try to mimic, as best as possible, some boundary conditions present in the neutralization facilities of both companies, such as the target $\mathrm{pH}$ value and the retention time of the reactant dispersed in the wastewater. Additionally, since the goal was to test the by-products for a future industrial application, the minimum number of alterations was done to the samples, and only materials retrieved by the companies were used. In fact, the fewer operations are performed on the samples, the more the materials comply with the state of the art of the process, thus, the lower the economic impact of changes in the process. Additionally, the interest is focused mostly on landfill slags, since they are at their end of life as a product, and utilizing them introduces the least amount of changes to the current production process, while it maximizes the retained value of the byproducts.

The results of the experimental part are summarized by the following list:

- Four slags, two per each steel mill, were prepared with the use of crushing devices and a sieve. They were also characterized based on the PSD, along with two lime samples used in the current neutralization industrial process at OTK and SMT. Wastewaters samples were also acquired from the companies.

- All slag samples were tested with a stepwise dosing method, in order to measure the minimum amount of material needed to raise the $\mathrm{pH}$ of the industrial acidic wastewaters to a value of $9 \pm 2$. 
Two of them, one per company, raised the $\mathrm{pH}$ to the target value. The lime samples were also tested with the same method for reference. With this method, approximately 4.4 times the amount of slag was needed, compared to the amount of lime.

- The quantities measured during the successful trials in the stepwise dosing trials were used as a benchmark for a second experiment, named single-step dosing. This method differed from the previous one in terms of reactant addition, while adding also a timeframe to achieve the $\mathrm{pH}$ target $(9 \pm 2$ in $30 \mathrm{~min})$, to mimic the industrial neutralization process. Only the slags that were successful in the previous experiments were used for the second one, while lime samples were once again used as a reference. The lime quantity needed to successfully raise the $\mathrm{pH}$ of the wastewaters did not change compared to the stepwise dosing method, while the quantities of slag were not sufficient to reach the target within the time limit; thus, more material was needed. This has been attributed to a slower kinetics for the reaction with slag compared to the one with lime. With this method, around eight times the amount of slag was needed compared to lime.

- The chemical composition of the clean waters produced after single-step dosing trials, obtained with the OTK slag sample, was measured with ICP-MS analysis and compared to the original composition of the OTK wastewaters, also measured with the same method. The concentrations of six elements ( $\mathrm{Cr}, \mathrm{Ni}, \mathrm{Mo}, \mathrm{F}, \mathrm{Fe}$, and $\mathrm{Zn}$ ) were measured and compared. The same procedure was used for clean waters produced with lime single-step dosing trials, as a reference. The slag sample proved capable of purifying the wastewaters to levels comparable to lime, and both the reactants managed to absorb the tested elements, reducing their concentrations in the waters below the legally permitted threshold values.

The results of the trials performed, despite applied at a laboratory scale, thus, far from the industrial case, provided solid evidence that the vision drafted has a strong practical counterpart. After seeing the results of these preliminary tests, it is believed that slag should be tested thoroughly, both from an applied point of view, by closing the gap between industrial and laboratory conditions, and from a theoretical point of view analyzing the neutralization mechanism and what parameters can be modified to increase the neutralization efficiency. The two slags that could not reach the target $\mathrm{pH}$ value should not be excluded from the list of possible reactants, but more experiments with a finer and more homogenized PSD distribution across all the samples are needed to have a definite answer. Once single-step dosing trials are re-done, the samples used should be analyzed through XRD and SEM, to provide their complete characterization. Once the mineral content is characterized, it is possible to correlate it with the neutralization efficiency of the samples with a homogenous PSD. ICP-MS analysis on the slag samples was deemed unfit to the scope, because the mineral structure is not taken into account by this type of analysis, since it only measures the pure chemical composition. In particular, focusing only on the total amount of Ca present in the slag sample without considering how it is bound to other elements is not sufficient to draw any conclusions.

This paper analyzes and presents experiments done via the route represented on the left-hand side of Figure 4, since it presents the first obstacle to achieving a zero-waste EAF process, even though more experiments need to be done on the second path, which revolves around the re-use of the saturated slag in the steelmaking process. First, it is important to understand their mineral composition; therefore, XRD and SEM are once again needed for a complete characterization. If the sediments will be used for high-temperature processes above their melting point, for instance as slag builders, then an ICP-MS may be sufficient. Saturated lime (since it is rich in $\mathrm{CaF}_{2}$ after the neutralization) has already been used as a slag builder by OTK, and the authors believe similar applications can be applied for saturated slag as well, hence the reason why F removal was tested in the water purity trials. Even though it is only possible to address a possible use for the sediments by first understanding the mineral content, it is also not difficult to imagine that closing the loop of slag generates difficulties, as well as opening up many questions regarding the degradation of the material over time and how it can impact the process and the steel quality. 
To conclude, rather than providing a full overview of a process change, this paper aims to be the stepping stone towards the adoption of a new technology that could start the transition towards a zero-waste production of stainless-steel. The experimental trials presented are only the first investigation of many to come to provide the industry and the research community with comprehensive answers regarding this new approach to slag valorization.

Author Contributions: Conceptualization, A.G., M.D.C. and P.J.; methodology, A.G. and M.D.C.; validation, M.D.C. P.J., A.K. and A.G.; investigation, M.D.C., P.J., A.G. and A.K.; resources, P.J.; writing-original draft preparation, M.D.C., P.J., A.G. and A.K.; writing-review and editing, A.R., G.R.; supervision, P.J., A.G. and A.K.; project administration, P.J.; funding acquisition, P.J.

Funding: This research received no external funding.

Conflicts of Interest: The authors declare no conflict of interest.

\section{References}

1. Crutzen, P.J. Geology of mankind The Anthropocene. Nature 2002, 415, 22-23. [CrossRef] [PubMed]

2. Rockström, J.; Steffen, W.; Noone, K.; Persson, Å.; Chapin, F.S.I.I.I.; Lambin, E.; Lenton, T.M.; Scheffer, M.; Folke, C.; Schellnhuber, H.J.; et al. Planetary Boundaries: Exploring the Safe Operating Space for Humanity. Ecol. Soc. 2009, 14, 32. [CrossRef]

3. Hultman, J.; Corvellec, H. The European Waste Hierarchy: From the Sociomateriality of Waste to a Politics of Consumption. Environ. Plan. Econ. Space 2012, 44, 2413-2427. [CrossRef]

4. Lansink, A. Challenging Changes-Connecting Waste Hierarchy and Circular Economy. Waste Manag. Res. 2018, 36, 872. [CrossRef]

5. Van Ewijk, S.; Stegemann, J.A. Limitations of the waste hierarchy for achieving absolute reductions in material throughput. J. Clean. Prod. 2016, 132, 122-128. [CrossRef]

6. Pålsson, K.; Sweden, O.; Stemne, J.; Ruist, G.; Blixt, E. Stålindustrin Gör Mer än Stål. Handbok för Restprodukter 2018; Jernkontoret: Stockholm, Sweden, 2018.

7. Geiseler, J. Use of Steelwork Slag in Europe. Waste Manag. 1996, 16, 59-63. [CrossRef]

8. Autelitano, F.; Giuliani, F. Electric arc furnace slags in cement-treated materials for road construction: Mechanical and durability properties. Constr. Build. Mater. 2016, 113, 280-289. [CrossRef]

9. Engström, F.; Larsson, M.L.; Samuelsson, C.; Sandström, Å.; Robinson, R.; Björkman, B. Leaching Behavior of Aged Steel Slags. Steel Res. Int. 2014, 85, 607-615. [CrossRef]

10. Santoro, L.; Volpicelli, G.; Caprio, V. Limestone neutralization of acid waters in the presence of surface precipitates. Water Res. 1987, 21, 641-647. [CrossRef]

11. Foxon, T.J. Technological Lock-In. In Encyclopedia of Energy, Natural Resource, and Environmental Economics; Elsevier: Amsterdam, The Netherlands, 2013; pp. 123-127.

12. Fogelström, J.B.; Pousette, H. Neutralizing Acidic Wastewater From the Pickling Process Using Slag from the Steelmaking Process. Master's Thesis, KTH Royal Institute of Technology, Stockholm, Sweden, 2017.

13. Yang, H.F.; Ou, Q.F.; Zhou, F. Steel Slag as Neutralization-Adsorption Material for Treatment of Acidic Zn2+-Containing Wastewater. Adv. Mater. Res. 2012, 383, 3416-3421. 